\title{
Hypoxic pulmonary blood flow redistribution and arterial oxygenation in endotoxin-challenged NOS2-deficient mice
}

\author{
Roman Ullrich, ${ }^{1}$ Kenneth D. Bloch, ${ }^{2}$ Fumito Ichinose, ${ }^{1}$ Wolfgang Steudel, ${ }^{1}$ \\ and Warren M. Zapol ${ }^{1}$ \\ ${ }^{1}$ Department of Anesthesia and Critical Care, and
${ }^{2}$ Cardiovascular Research Center, Department of Medicine, Massachusetts General Hospital, Harvard Medical School,
Boston, Massachusetts 02114, USA \\ Address correspondence to: Warren M. Zapol, Department of Anesthesia and Critical Care, Massachusetts General Hospital, \\ Harvard Medical School, 32 Fruit Street, Boston, Massachusetts 02114, USA. \\ Phone: (617) 726-3030; Fax: (617) 726-3032; E-mail: zapol@etherdome.mgh.harvard.edu.
}

Received for publication February 18, 1999, and accepted in revised form October 7, 1999.

\begin{abstract}
Sepsis and endotoxemia impair hypoxic pulmonary vasoconstriction (HPV), thereby reducing arterial oxygenation and enhancing hypoxemia. Endotoxin induces nitric oxide (NO) production by NO synthase 2 (NOS2). To assess the role of NO and NOS2 in the impairment of HPV during endotoxemia, we measured in vivo the distribution of total pulmonary blood flow (QPA) between the right (QRPA) and left (QLPA) pulmonary arteries before and after left mainstem bronchus occlusion (LMBO) in mice with and without a congenital deficiency of NOS2. LMBO reduced QLPA/QPA equally in saline-treated wild-type and NOS2deficient mice. However, prior challenge with Escherichia coli endotoxin markedly impaired the ability of LMBO to reduce QLPA/QPA in wild-type, but not in NOS2-deficient, mice. After endotoxin challenge and $\mathrm{LMBO}$, systemic oxygenation was impaired to a greater extent in wild-type than in NOS2-deficient mice. When administered shortly after endotoxin treatment, the selective NOS2 inhibitor L-NIL preserved HPV in wild-type mice. High concentrations of inhaled NO attenuated HPV in NOS2-deficient mice challenged with endotoxin. These findings demonstrate that increased pulmonary NO levels (produced by NOS2 or inhaled at high levels from exogenous sources) are necessary during the septic process to impair HPV, ventilation/perfusion matching and arterial oxygenation in a murine sepsis model.
\end{abstract}

J. Clin. Invest. 104:1421-1429 (1999).

\section{Introduction}

The normal pulmonary vasculature constricts in response to alveolar hypoxia. In contrast, systemic vessels vasodilate in response to hypoxia. Hypoxic pulmonary vasoconstriction (HPV) preserves systemic arterial oxygenation by redistributing blood flow away from collapsed or poorly ventilated lung regions toward wellventilated lung regions, thereby matching pulmonary ventilation $(\mathrm{V})$ with perfusion $(\mathrm{Q})$.

The mechanisms responsible for HPV are intrinsic to pulmonary vascular smooth muscle cells: HPV does not appear to require the presence of an intact endothelium (1). Vasoactive mediators released from a variety of pulmonary sources, including the endothelium and circulating cells, are important modulators of the pulmonary vascular response to hypoxia (2). Nitric oxide (NO) was identified as the endothelium-derived relaxing factor (EDRF) released from arteries and veins (3). NO synthases (NOSs) produce NO by conversion of Larginine to L-citrulline. Constitutive NOSs, NOS1 and NOS3 (initially isolated from neurons and endothelial cells, respectively), are calcium/calmodulin dependent and produce low levels of NO that regulate homeostatic processes and contribute to the low pulmonary vascular resistance (PVR) $(4,5)$. Acute inhibition of endogenous NO production has been shown to enhance HPV in normal animals (6), and inhaled NO reverses human HPV (7).
In addition to its vasoregulatory function, NO participates in the response to inflammatory stimuli (8). Exposure to cytokines, such as IL- $1 \beta$ and TNF- $\alpha$, or microbial products, such as endotoxin, stimulates cells to express an inducible NOS (NOS2) that generates greater amounts of NO than the constitutive isoforms (9). It is well established that the same inflammatory mediators that induce NOS2 also attenuate HPV, resulting in increased blood flow to poorly ventilated lung regions (V/Q mismatching), augmented right-to-left shunting of venous blood, and reduced arterial oxygenation (10).

The role of $\mathrm{NO}$ in the impairment of HPV during endotoxemia and sepsis is incompletely understood. The existing evidence is controversial, with reports suggesting that HPV is either increased $(11,12)$ or unchanged $(13,14)$ after acute inhibition of NO formation with L-arginine analogs during sepsis. After an endotoxin challenge, suppression of NOS2 expression with dexamethasone and inhibition of NOS2 activity by administration of L-arginine analogs restore vascular reactivity to vasoconstrictors in both systemic (15) and pulmonary vessels (16). However, the use of L-arginine analogs or dexamethasone to evaluate the role of NOS2 in the endotoxin-induced impairment of HPV is limited by the incomplete specificity of these agents for NOS2. To identify a role for NOS2 in the endotoxin-induced impairment of HPV, we compared the ability to redistribute pulmonary blood flow after left mainstem bronchus occlusion (LMBO) in wild-type mice 
and in mice with a congenital deficiency of NOS2. We report that NOS2 deficiency protects mice from endotoxin-induced impairment of HPV. In endotoxin-treated NOS2-deficient mice, replacement of molecular NO in the lung by breathing 40 parts per million (ppm) NO for 22 hours impaired HPV when measured 1 hour after discontinuing NO inhalation, but did not effect LMBOinduced pulmonary blood flow redistribution in endotoxin-treated wild-type mice or untreated mice of either strain.

\section{Methods}

After institutional approval by the Massachusetts General Hospital Subcommittee on Research Animal Care, we studied SV129/B6F1 wild-type mice (F1-generation progeny of SV129 and C57 BL/6 mice) and SV129 wildtype mice (The Jackson Laboratory, Bar Harbor, Maine, USA), as well as NOS2-deficient mice with a SV129 and C57BL/ 6 hybrid background (17) (generously provided by C. Nathan, Cornell University, New York City, New York, USA). In supplemental studies, NOS2-deficient mice (18), backcrossed 10 generations onto a C57BL/6 background (C57BL/6-Nos2 ${ }^{\text {tmlLau }}$, N10-backcross generation; The Jackson Laboratory), and wild-type C57BL/6 were studied.

\section{Experimental groups}

Experimental groups matched for animal age, body weight, and sex are described here. Male and female mice with an age range of 2-5 months, weighing 18-30 g, were studied.

Group 1: controls. SV129/B6F1 wild-type mice $(n=5)$, SV129 wild-type mice $(n=7)$, and NOS2-deficient mice $(n=7)$ received an intraperitoneal injection of $0.2 \mathrm{~mL}$ saline and were studied 22 hours later.

Group 2: endotoxin-treated. SV129/B6F1 wild-type mice $(n=5)$, SV129 wild-type mice $(n=6)$, and NOS2-deficient mice $(n=6)$ were studied 22 hours after a challenge with an intraperitoneal injection of $10 \mathrm{mg} / \mathrm{kg}$ Escherichia coli 011B4 endotoxin dissolved in $0.2 \mathrm{~mL}$ saline. Additionally, C57BL/ 6 wild-type mice $(n=7)$ and C57BL/6-Nos $2^{\text {tmlLau }}$ mice $(n=5)$ were studied 22 hours after a challenge with an intraperitoneal injection of $10 \mathrm{mg} / \mathrm{kg}$ endotoxin dissolved in $0.2 \mathrm{~mL}$ saline.

Group3: endotoxin-treated + L-NIL. SV129/B6F1 wild-type mice $(n=5)$ were injected intraperitoneally with $10 \mathrm{mg} / \mathrm{kg}$ E. coli $011 \mathrm{~B} 4$ endotoxin dissolved in $0.2 \mathrm{~mL}$ saline. Three hours after the endotoxin challenge, mice were treated with L-NIL $5 \mathrm{mg} / \mathrm{kg}$ intraperitoneally. Studies were performed 22 hours after the endotoxin challenge. In additional SV129/B6F1 mice with $(n=5)$ and without $(n=4)$ a prior challenge of endotoxin (22 hours earlier), the acute response to an intravenous bolus of $5 \mathrm{mg} / \mathrm{kg} \mathrm{L-NIL}$ administered during LMBO, was studied. We chose a dose of $5 \mathrm{mg} / \mathrm{kg}$ intraperitoneal L-NIL because similar doses have been shown to effectively inhibit NOS2 activity in vivo in rodent models of inflammation (19).

Group 4: prolonged exposure to 4 or 40 ppm NO. Salinetreated SV129 wild-type mice $(n=5)$ and NOS2-deficient mice $(n=5)$ breathed 40 ppm NO in air for 22 hours and were studied 1 hour after discontinuation of $\mathrm{NO}$ inhalation. SV129 wild-type mice $(n=5)$ and NOS2-deficient mice $(n=5)$ breathed $40 \mathrm{ppm} \mathrm{NO}$ in air for 22 hours after challenge with $10 \mathrm{mg} / \mathrm{kg}$ endotoxin intraperitoneally and were studied 1 hour after discontinuation of NO inhalation. Additional NOS2-deficient mice $(n=4)$ breathed 4 ppm of NO in air for 22 hours after challenge with 10 $\mathrm{mg} / \mathrm{kg}$ endotoxin intraperitoneally and were studied 1 hour after discontinuation of $\mathrm{NO}$ inhalation.

Group 5: continuous $\mathrm{PaO}_{2}$ and $\mathrm{PvO}_{2}$ measurements. $\mathrm{PaO}_{2}$ was assessed continuously before and during $\mathrm{LMBO}$ in SV129/B6F1 wild-type mice $(n=3)$ and NOS2-deficient mice $(n=3) 22$ hours after challenge with $10 \mathrm{mg} / \mathrm{kg}$ endotoxin intraperitoneally. $\mathrm{PvO}_{2}$ was assessed continuously before and during LMBO in SV129/B6F1 wildtype mice $(n=4)$ and NOS2-deficient mice $(n=4) 22$ hours after challenge with $10 \mathrm{mg} / \mathrm{kg}$ endotoxin intraperitoneally. In saline-treated SV129 wild-type mice, $\mathrm{PaO}_{2}(n=4)$ and $\mathrm{PvO}_{2}(n=4)$ were studied before and during $\mathrm{LMBO}$ under control conditions, without a prior challenge of endotoxin.

Group 6: pulmonary vascular response to increasing doses of intravenous angiotensin II. SV129/B6F1 wild-type mice treated with endotoxin $(n=5)$ or with saline $(n=3)$ were studied 22 hours after the challenge.

Experimental preparation. Mice were anesthetized by intraperitoneal injection of ketamine $(0.1 \mathrm{mg} / \mathrm{g}$ body weight $[\mathrm{bw}])$. Tracheostomy and arterial catheterization were performed as described previously (20). A custommade endotracheal tube (22G Angiocath; Becton Dickinson Healthcare Systems, Sandy, Utah, USA), combined with a 2 French Fogarty arterial embolization catheter (Baxter Healthcare Corp., Irvine, California, USA) was inserted into the trachea, with the balloon tip of the Fogarty catheter initially remaining in the trachea. Volume-controlled ventilation was initiated at a respiratory rate of $110-120$ breaths per minute, at $\mathrm{FiO}_{2}$ 1.0, a peak inspiratory pressure of 13 $\mathrm{cm} \mathrm{H}_{2} \mathrm{O}$, and a positive end-expiratory pressure level of 2-3 $\mathrm{cm} \mathrm{H}_{2} \mathrm{O}$. A right parasternal thoracotomy was performed, and a small-vessel ultrasonic flow probe (1RB; Transonic Instruments, Ithaca, New York, USA) was placed around the right pulmonary artery and fixed in position using a micromanipulator (X-tra Hand; TechniTool, Plymouth, Pennsylvania, USA). A 4-0 silk suture was positioned around the left main pulmonary artery to allow transient vascular occlusion. A pulmonary artery catheter (PE10) was inserted into the main pulmonary artery by direct puncture. In other experiments, a lower thoracic aortic flow probe was placed as reported previously (20).

In some studies, the pulmonary vein draining the right middle lobe was punctured with a $30 \mathrm{G}$ needle, connected to PE10 tubing, and secured with a microclip to assess left atrial pressure $\left(\mathrm{P}_{\mathrm{LA}}\right)$. To measure the partial pressure of oxygen in the aorta $\left(\mathrm{PaO}_{2}\right)$, a flexible polarographic Clark-type $\mathrm{PO}_{2}$ electrode (LICOX A3-Revoxode, 1.5 Fr.; GMS-Gesellschaft fuer medizinische Sondentechnik, Kiel, Germany), was advanced into the aortic arch via the carotid artery. To measure the partial pressure of oxygen in the pulmonary artery $\left(\mathrm{PvO}_{2}\right)$, the right ventricular outflow tract was punctured, and the oxygen electrode was advanced into the pulmonary artery. Electrodes were calibrated before and after each experiment in air at ambient pressure using a test probe barrel. Anesthesia was maintained with intraperitoneal ketamine $(0.1 \mathrm{mg} / \mathrm{g}$ bw) and xylazine $(0.01 \mathrm{mg} / \mathrm{g} \mathrm{bw})$ injections with 
intraperitoneal pancuronium $(0.002 \mathrm{mg} / \mathrm{g} \mathrm{bw})$ added to produce muscle relaxation.

Blood flow and pressure measurements. Mean systemic arterial pressure $\left(\mathrm{P}_{\mathrm{SA}}\right)$, mean pulmonary artery pressure $\left(\mathrm{P}_{\mathrm{PA}}\right)$, and in some studies $\mathrm{P}_{\mathrm{LA}}$, were continuously monitored using biomedical amplifiers (Hewlett Packard 8805C, Palo Alto, California, USA; and Siemens Sirecust 960, Danvers, Massachusetts, USA). Mean lower thoracic aortic flow (QLTAF) and right pulmonary artery flow (QRPA) were measured with small vessel flow probes connected to a flowmeter (T106; Transonic Instruments). In some experiments, left ventricular end-diastolic pressure was measured with a 1.4 Fr. Millar catheter. The catheter was advanced through the right carotid artery into the left ventricle. All measured signals were transferred to an analog-to-digital converter, displayed on a computer screen, and recorded at $640 \mathrm{~Hz}$ using a data acquisition system (DI 220; Dataq Instruments, Akron, Ohio, USA) on a personal computer. All monitoring equipment was calibrated before each experiment.

Interventions during hemodynamic experiments

Differential measurement of left and right pulmonary artery flow. To assess the contribution of QRPA and left pul- monary artery flow (QLPA) to total pulmonary artery flow (QPA), transient occlusion (90 seconds) of the left pulmonary artery (QLPA) was performed. QRPA during acute left pulmonary artery occlusion was considered to be QPA (i.e., cardiac output) and correlated closely $\left(\mathrm{r}^{2}=\right.$ $0.88 ; y=0.95 x+0.38 ; n=9)$ with QLTAF. QLPA was calculated as the difference between QRPA during left pulmonary artery occlusion (QPA) and QRPA with a patent left pulmonary artery (QLPA = QPA - QRPA). Absolute values of respective flows were recorded, and the fractional distribution of flow to the right and left lungs (QRPA/QPA and QLPA/QPA) was calculated.

QPA was assessed by measurement of QRPA during transient occlusion of the left pulmonary artery (QLPA) because blood flow is lost to the upper extremities and the head when measured at the lower thoracic aorta. Moreover, adding a second flow probe increases the likelihood of error, because of the small size of the mouse, and increases surgical trauma and stress to the animal.

Unilateral alveolar bypoxia. To induce regional (i.e., left lung) alveolar hypoxia, the left mainstem bronchus was reversibly occluded (LMBO) by advancing a Fogarty catheter into the left mainstem bronchus and inflating the balloon tip under visual control. Complete collapse a

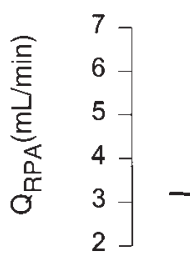

b

C
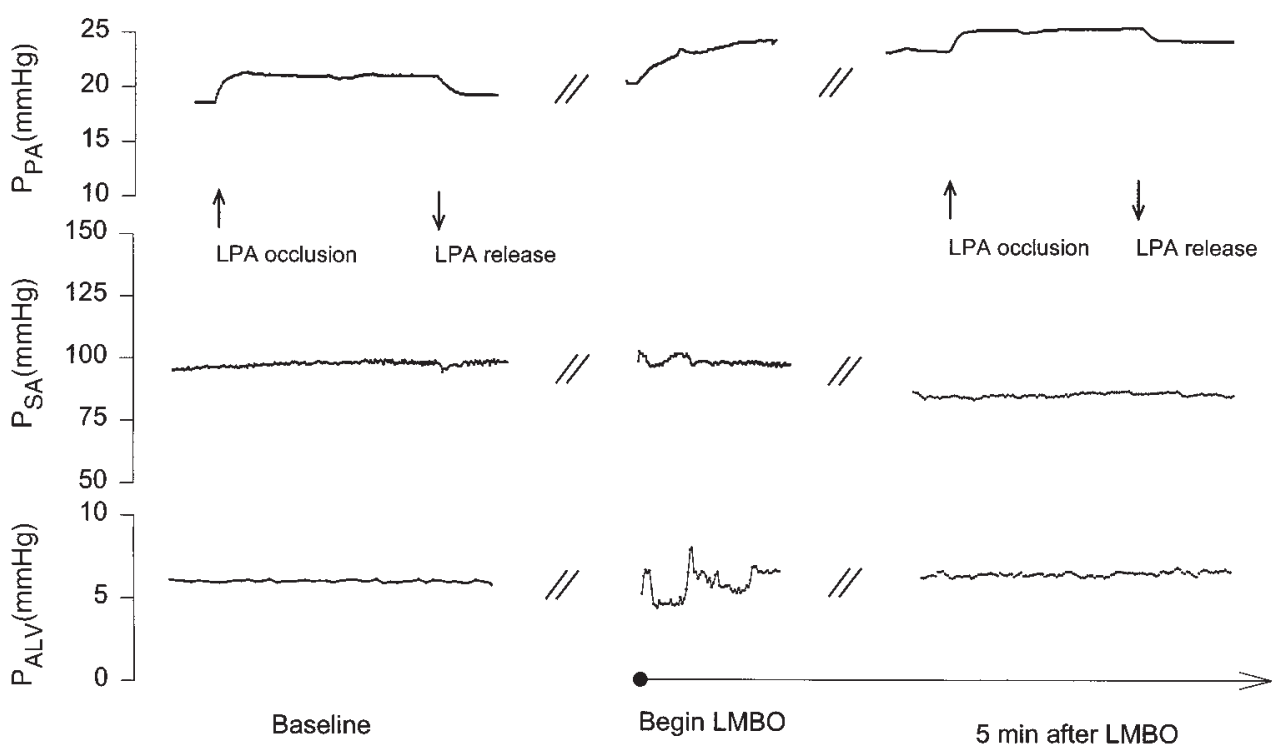

Figure 1

Representative tracings of pulmonary and systemic hemodynamic measurements before and during LMBO with and without transient left pulmonary artery (LPA) occlusion. Effects of unilateral alveolar hypoxia induced by LMBO on central hemodynamics before (a) and during LMBO (b and $\mathbf{c}$ ) are portrayed. Total alveolar collapse occurred about 1 minute after LMBO. Online recordings of mean flow through the right pulmonary artery (QRPA), mean pulmonary artery pressure $\left(\mathrm{P}_{\mathrm{PA}}\right)$, mean systemic arterial pressure $\left(\mathrm{P}_{\mathrm{SA}}\right)$, and mean airway pressure $\left(\mathrm{P}_{\mathrm{ALV}}\right)$ in a saline-treated wild-type mouse at baseline and after $L M B O$. To assess blood flow distribution between right and left pulmonary arteries, the left pulmonary artery was transiently occluded, at which point QRPA = QPA (see $\mathbf{a}$ and $\mathbf{c}$ ). The difference of QPA - QRPA equals QLPA. Measurements were taken at baseline and 5 minutes after $\mathrm{LMBO}$. Arrows indicate occlusion ( 90 seconds) and release of left pulmonary artery. 

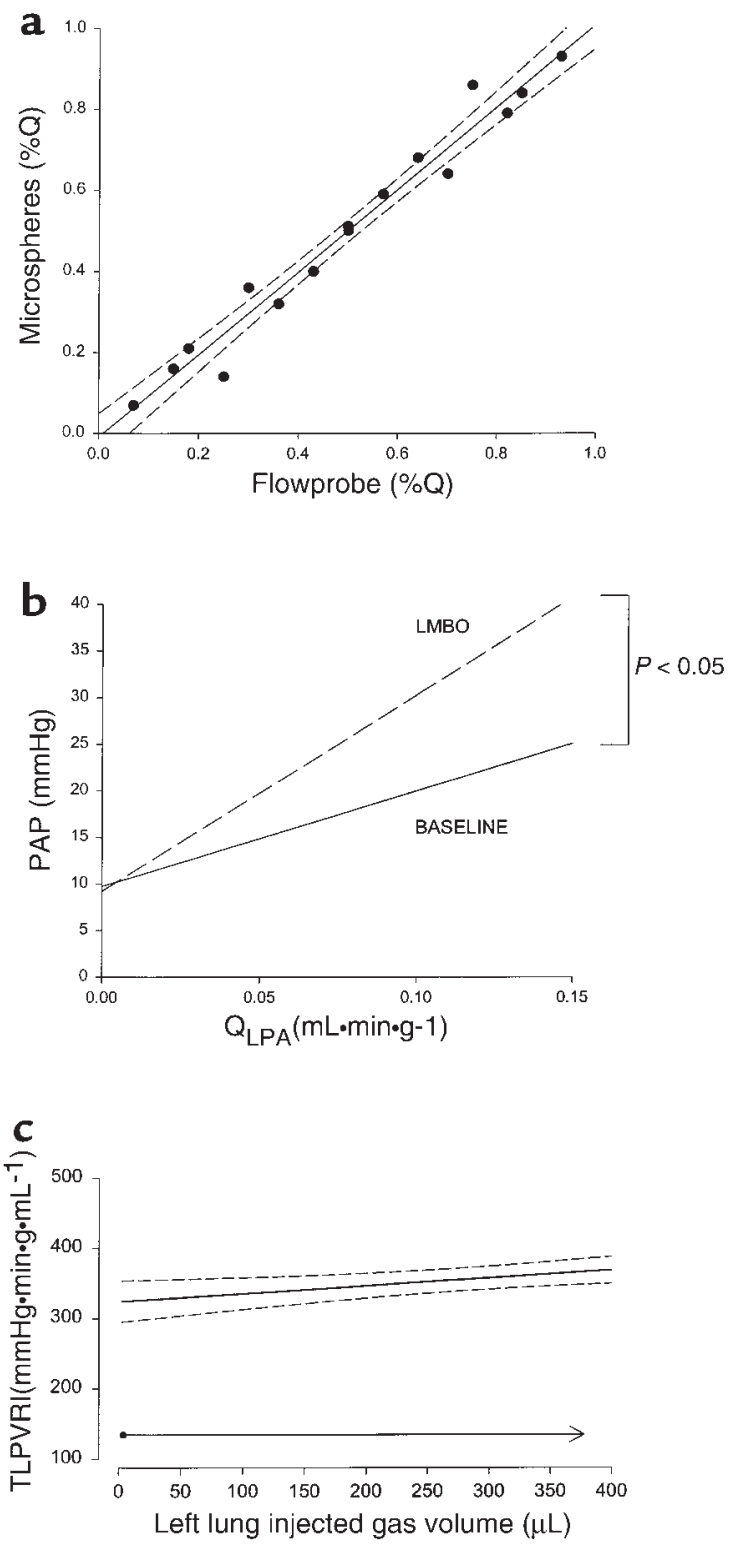

Figure 2

(a) Correlation of percent pulmonary blood flow to the left or right lung assessed by intravenous injection of fluorescent microspheres $(15 \mu \mathrm{m})$ and by simultaneous measurement of QRPA with an ultrasonic flow probe. In the latter method, differential blood flow distribution between the right and left pulmonary artery was assessed by transient occlusion of the left pulmonary artery, as described in the legend to Figure 1. Values are expressed as the fractional flow to the right or left lung before and after LMBO (saline-treated wild-type mice; $n=4$ ). Note the close agreement between the 2 methods $\left(r^{2}=0.967\right)$. (b) The left lung pulmonary flow-pressure relationship before (baseline) and after 5 minutes of LMBO in saline-treated wild-type mice $(n=6)$. Note the significant increase of the slope, which represents an increased incremental left lung pulmonary vascular resistance induced by LMBO. Left pulmonary artery flow (QLPA) was measured by an ultrasonic flow probe, and the slopes were generated by reducing QPA with a transient occlusion of the inferior vena cava $(P<0.05$, slope differs versus baseline). (c) Changes in total left lung pulmonary vascular resistance (TLPVR) during re-expansion of the collapsed left lung in saline-treated wild-type mice $(n=3)$. The left lung was inflated by a continuous injection of $5 \% \mathrm{CO}_{2}$ in $\mathrm{N}_{2}$ up to a peak inspiratory pressure of $30 \mathrm{~cm} \mathrm{H}_{2} \mathrm{O}$. Values are expressed as a linear regression of all data points with the respective $95 \%$ confidence intervals. of the left lung was visually observed within about a minute and confirmed by transient overinflation of the right lung. $\mathrm{P}_{\mathrm{PA}}, \mathrm{P}_{\mathrm{SA}}$, and $\mathrm{QRPA}$ were continuously measured during LMBO. In some experiments, the collapsed left lung was reinflated with $5 \% \mathrm{CO}_{2}$ in $\mathrm{N}_{2}$ to a peak airway pressure of $30 \mathrm{~cm} \mathrm{H}_{2} \mathrm{O}$. QLPA was measured before and 5 minutes after LMBO.

Infusion of angiotensin II. Increasing doses of angiotensin II $(0.05,0.5$, and $5.0 \mathrm{ng} / \mathrm{g}$ bw per minute) dissolved in sterile normal saline were infused via the central venous catheter using an infusion pump (Pump 11; Harvard Apparatus Co., South Natick, Massachusetts, USA). $P_{\text {LA, }}$ $\mathrm{P}_{\mathrm{PA}}, \mathrm{P}_{\mathrm{SA}}$, and QLTAF were continuously measured.

Breathing with supplemental NO. Mice were housed in specially constructed chambers (20) where they breathed spontaneously for 22 hours at an inspired oxygen fraction $\left(\mathrm{FiO}_{2}\right)$ of 0.21 with $40 \mathrm{ppm} \mathrm{NO}$ added to the inspiratory gas mixture. After exposure, mice were removed from the chambers and breathed air during the induction of anesthesia. Hemodynamic measurements were obtained 60 minutes after removal from the chambers. During measurements, animals were mechanically ventilated at $\mathrm{FiO}_{2} 1.0$ without supplemental NO.

Validation of pulmonary blood flow measurements. In salinetreated wild-type mice $(n=5)$, we compared simultaneous measurements of fractional pulmonary blood flow distribution made using intravenous injections of fluorescent-labeled microspheres (23) with those made using ultrasonic flow probes, as already described here. Before LMBO, 50,000 colored microspheres $(15-\mu \mathrm{m}$ NuFlow Spheres; Interactive Medical Technologies Ltd., West Los Angeles, California, USA), suspended in $0.2 \mathrm{~mL}$ saline containing $0.05 \%$ Tween- 80 surfactant to prevent aggregation, were vortexed and then immediately infused (over 30 seconds) through a jugular vein cannula. After completion of the injection, the catheter was flushed with 0.1 $\mathrm{mL}$ saline. After 5 minutes of LMBO, microsphere injection was repeated using microspheres of a different color. Animals were sacrificed, and the lungs were harvested and weighed separately. Tissue samples were analyzed for total microsphere counts using flow cytometric analysis. The fraction of pulmonary blood flow to the right or left lung was calculated as total spheres to right or left lung over total spheres in both lungs.

In additional saline-treated wild-type mice $(n=6)$, to confirm that the LMBO-induced redistribution of pulmonary blood flow was reflected by an increase in left pulmonary vascular resistance, we directly measured QLPA during transient occlusion of the inferior vena cava and calculated the slope and intercept of the left pulmonary artery pressure-flow relationship.

Lung wet/dry ratio. After euthanasia with pentobarbital $(0.1 \mathrm{mg} / \mathrm{g}$ intraperitoneally), both lungs, excluding hilar structures, were excised, blotted, and immediately weighed. Thereafter, the tissue was dried in a microwave oven for 60 minutes, as described previously (20), and reweighed. Lung wet/dry ratio was calculated.

Statistical analysis. Changes of pulmonary blood flow are expressed as the percent reduction of baseline blood flow. Differences between groups were determined using a 2-way ANOVA. When significant differences were detected by ANOVA, a post hoc Fisher's test was used 
(Statistica for Windows; StatSoft Inc., Tulsa, Oklahoma, USA). A $P$ value of less than 0.05 indicated a significant difference. All data are expressed as mean \pm SEM.

\section{Results}

Effects of unilateral alveolar bypoxia on pulmonary blood flow. To assess HPV in vivo, we developed a murine model in which differential pulmonary blood flow measurements could be obtained before and during left lung unilateral alveolar hypoxia (Figure 1). Because occlusion of the right mainstem bronchus caused severe hypoxemia and hemodynamic instability, we elected to occlude the left mainstem bronchus (LMBO), which produced a stable model of unilateral lung collapse. Differential pulmonary blood flow was measured at thoracotomy using an ultrasonic flow probe placed around the right pulmonary artery, and the flow distribution between the right and left lung was assessed by transiently occluding the left pulmonary artery (Figure 1). Transient occlusion of left pulmonary artery flow did not produce any systemic hemodynamic effect (data not shown). HPV was assessed as the percent decrease in QLPA/QPA at 5 minutes after LMBO. Measurements of pulmonary blood flow distribution using a flow probe correlated closely with measurements using intravenous injections of fluorescent microspheres $\left(r^{2}=0.97\right.$; Figure $\left.2 a\right)$.

Before LMBO, hemodynamic parameters did not differ between wild-type mice and NOS2-deficient mice. Five minutes after LMBO, QLPA/QPA was reduced by 46 $\pm 5 \%$ in saline-treated wild-type mice and by $50 \pm 7 \%$ in saline-treated NOS2-deficient mice (Figure 3). In supplemental studies in which QLPA was measured directly using a flow probe around the left pulmonary artery, we observed that the LMBO-induced pulmonary blood flow redistribution was reflected by an increase in incremental left pulmonary vascular resistance from $102 \pm 18$ $\mathrm{mmHg} \bullet \mathrm{min} \bullet \mathrm{g} \bullet \mathrm{mL}^{-1}$ to $210 \pm 38 \mathrm{mmHg} \bullet \mathrm{min} \bullet \mathrm{g} \bullet \mathrm{mL}^{-1}$ (Figure 2b). LMBO-induced pulmonary blood flow redistribution was not attributable to mechanical factors associated with left lung collapse, as left pulmonary vascular resistance (LPVR) did not change when the collapsed lung was reinflated to a normal lung volume under direct vision with $5 \% \mathrm{CO}_{2}$ in $\mathrm{N}_{2}(n=3$; Figure $2 \mathrm{c})$. Effect of endotoxemia on pulmonary and systemic hemodynamics during unilateral alveolar bypoxia. After challenge with intraperitoneal injection of $10 \mathrm{mg} / \mathrm{kg}$ E. coli endotoxin, mice appeared lethargic with piloerection and diarrhea. Approximately $50 \%$ of mice died within 1 week after endotoxin challenge, and there were no differences in mortality between wild-type and NOS2deficient mice (data not shown). Before LMBO, hemodynamic parameters did not differ between saline-treated mice and endotoxin-treated mice (Table 1), but QPA tended to be higher in endotoxin-treated wild-type mice than in NOS2-deficient mice $(230 \pm 35$ vs. $\left.120 \pm 32 \mu \mathrm{L} \bullet \mathrm{min}^{-1} \bullet \mathrm{g}^{-1} \mathrm{bw}\right)$, although this difference did not reach statistical significance. Comparison of QPA for all studied endotoxin-challenged wild-type and NOS2-deficient mice confirmed that there was no difference between the two genotypes (wild-type mice $180 \pm 20 \mu \mathrm{L} / \mathrm{min}$ per gram; NOS2-deficient mice $140 \pm$ $15 \mu \mathrm{l} / \mathrm{min}$ per gram; $n=21$ and 15 , respectively). Because differences in QPA potentially affect pulmonary blood flow redistribution, we tested whether changes in QLPA/QPA depended on changes in QPA. Linear regression analysis revealed no correlation between QPA and QLPA/QPA during LMBO $\left(\mathrm{r}^{2}=0.03\right.$, both for all mice and for all endotoxin-treated mice). Five minutes after $\mathrm{LMBO}$, the fraction of blood flow directed to the hypoxic left lung (QLPA/QPA) was reduced by $46 \pm 5 \%$ in saline-treated wild-type mice and by $18 \pm 5 \%$ in endotoxin-treated wild-type mice $(P<$ 0.001 ; Figure 3). In contrast, LMBO reduced QLPA/QPA by $50 \pm 7 \%$ in saline-treated NOS2-deficient mice and by $51 \pm 6 \%$ in endotoxin-treated NOS2-deficient mice (Figure 3). There was no difference in the response to endotoxin between SV129, SV129B6F1, or C57BL/6 wild-type strains or between NOS2-deficient mice with SV129/B6F1-hybrid background and NOS2deficient mice backcrossed for 10 generations on a C57BL/ 6 background (data not shown).

Effect of endotoxemia on $\mathrm{PaO}_{2}$ and $\mathrm{PvO}_{2}$ during unilateral alveolar bypoxia. To determine whether the differences in LMBO-induced pulmonary blood flow redistribution

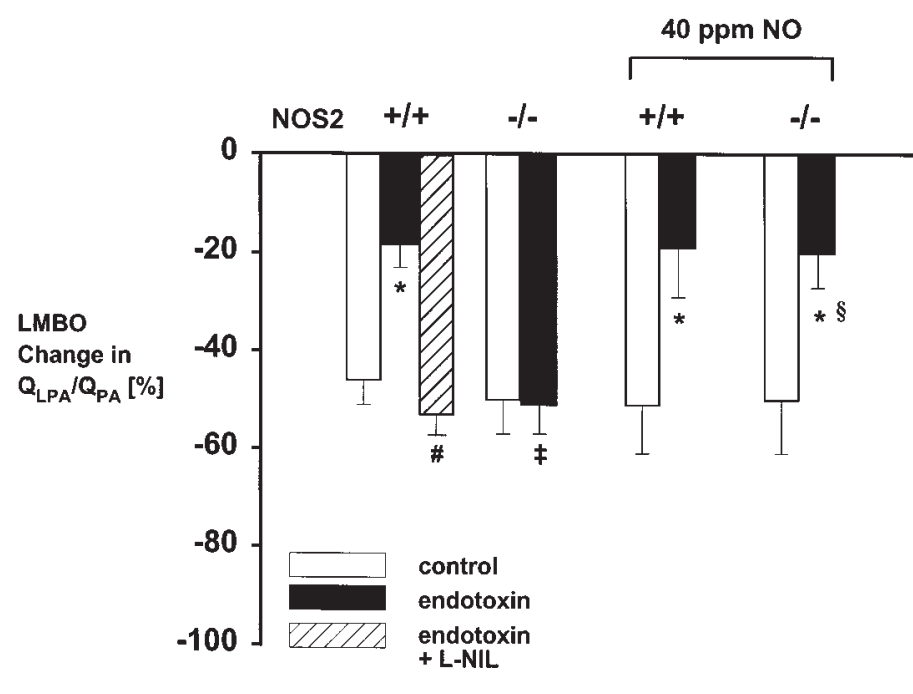

\section{Figure 3}

Change in fractional blood flow to the left lung (QLPA/QPA) 5 minutes after LMBO in wild-type mice $(+/+)$ and NOS2-deficient mice $(-/-)$ treated with saline (control, open bars; $n=7$ each), endotoxin (endotoxin, closed bars; $n=6$ each), or endotoxin with $5 \mathrm{mg} / \mathrm{kg} \mathrm{L-}$ NIL intraperitoneally (endotoxin with L-NIL, striped bar; $n=5$ ) 3 hours after the endotoxin challenge. $\left({ }^{*} P<0.05\right.$, endotoxin versus control; $¥ P<0.01$, wild-type versus NOS2-deficient; $\# P<0.01$ endotoxin + L-NIL versus endotoxin alone). Measurements were obtained following 1 hour after discontinuation of breathing air or 40 ppm NO in air for $22 \mathrm{~h}(\S P<0.05 \mathrm{NO}$ versus without $\mathrm{NO})$. Endotoxin challenge caused a marked reduction of pulmonary blood flow redistribution after LMBO in wild-type, but not in NOS2-deficient mice. After prolonged inhalation of 40 ppm NO, endotoxin-treated NOS2deficient mice, measured 1 hour after discontinuation of NO inhalation, showed the same loss of HPV as endotoxin-treated wild-type mice. Saline-treated NOS2-deficient mice and wild-type mice breathing 40 ppm NO for 22 hours retained their ability to redistribute pulmonary blood flow after LMBO, when measured 1 hour after discontinuing $\mathrm{NO}$ inhalation. 
noted in wild-type and NOS2-deficient mice after endotoxin challenge are reflected by differences in LMBOinduced changes in arterial oxygenation, the $\mathrm{PaO}_{2}$ was continuously measured before and during LMBO. In separate endotoxin-treated wild-type and NOS2-deficient mice, the effect of $\mathrm{LMBO}$ on $\mathrm{PvO}_{2}$ was also assessed. In saline-treated wild-type mice $(n=4)$, breathing at $\mathrm{FiO}_{2}$ 1.0, LMBO for 5 minutes decreased the $\mathrm{PaO}_{2}$ from $432 \pm 7 \mathrm{mmHg}$ to $225 \pm 13 \mathrm{mmHg}$. The $\mathrm{PaO}_{2}$ was $342 \pm 23 \mathrm{mmHg}$ in endotoxin-treated wild-type mice and $347 \pm 33 \mathrm{mmHg}$ in endotoxin-treated NOS2-deficient mice. After 5 minutes of LMBO, the $\mathrm{PaO}_{2}$ decreased more in endotoxin-treated wild-type mice $(145 \pm 9 \mathrm{mmHg})$ than in endotoxin-treated NOS2-deficient mice (230 $\pm 18 \mathrm{mmHg} ; P<0.05$; Figure 4).

$\mathrm{PvO}_{2}$ did not differ in endotoxin-treated wild-type mice and endotoxin-treated NOS2-deficient mice (before LMBO: $39 \pm 5$ and $44 \pm 8 \mathrm{mmHg}$, respectively; after LMBO: $34 \pm 4$ and $43 \pm 7 \mathrm{mmHg}$, respectively; $n=$ 3 for both groups).

Prolonged pharmacologic inhibition of NOS2 activity. To determine whether prolonged pharmacologic inhibition of NOS2 preserves HPV, wild-type mice $(n=5)$ were injected intraperitoneally with $10 \mathrm{mg} / \mathrm{kg}$ endotoxin, and 3 hours later were treated with L-NIL (5 $\mathrm{mg} / \mathrm{kg}$ intraperitoneally), a selective inhibitor of NOS2 activity. This dose of L-NIL was sufficient to prevent the increase in pulmonary cGMP levels in wild-type mice 7 hours after endotoxin challenge (data not shown). Pulmonary blood flow studies were performed 22 hours after the endotoxin challenge. In endotoxinexposed mice treated with L-NIL, we measured no dif- ferences in systemic and pulmonary hemodynamics before LMBO, compared with saline-treated or endotoxin-treated wild-type mice. The reduction of QLPA/QPA was greater in endotoxin-challenged wildtype mice treated with L-NIL than in wild-type mice treated with endotoxin alone $(53 \pm 10 \%$ vs. $18 \pm 5 \%$, respectively; $P<0.01$; Figure 3 ).

Acute pharmacologic inhibition of NOS2 with L-NIL. To determine whether acute inhibition of NOS2 enzyme activity augmented HPV during LMBO, pulmonary blood flow studies were performed in saline-treated and endotoxin-treated wild-type mice during which L-NIL (5 $\mathrm{mg} / \mathrm{kg}$ intravenously) was administered after LMBO. In saline-treated wild-type mice $(n=5)$, acute L-NIL administration did not further reduce QLPA/QPA during LMBO ( $49 \pm 3 \%$ before L-NIL; $56 \pm 3 \%$ after L-NIL). All other hemodynamic parameters did not change after LNIL injection. In wild-type mice treated with endotoxin 22 hours earlier $(n=4)$, acute L-NIL administration did not further reduce QLPA/QPA during LMBO $(22 \pm 11 \%$ reduction before L-NIL; $24 \pm 18 \%$ reduction after L-NIL).

Prolonged inhalation of 4 or 40 ppm NO. To learn whether increased pulmonary levels of $\mathrm{NO}$, rather than another NOS2 product, contribute to the endotoxin-induced impairment of HPV, saline-treated and endotoxin-challenged wild-type and NOS2-deficient mice breathed 40 ppm NO in air for 22 hours. The hemodynamic studies were performed 1 hour later, allowing ample time for any potential vasodilator action of inhaled NO to dissipate. Inhalation of 40 ppm NO for 22 hours did not impair HPV in saline-treated wild-type mice and NOS2-deficient mice: reduction of QLPA/QPA after LMBO was $51 \pm 10 \%$

Table 1

Hemodynamic measurements

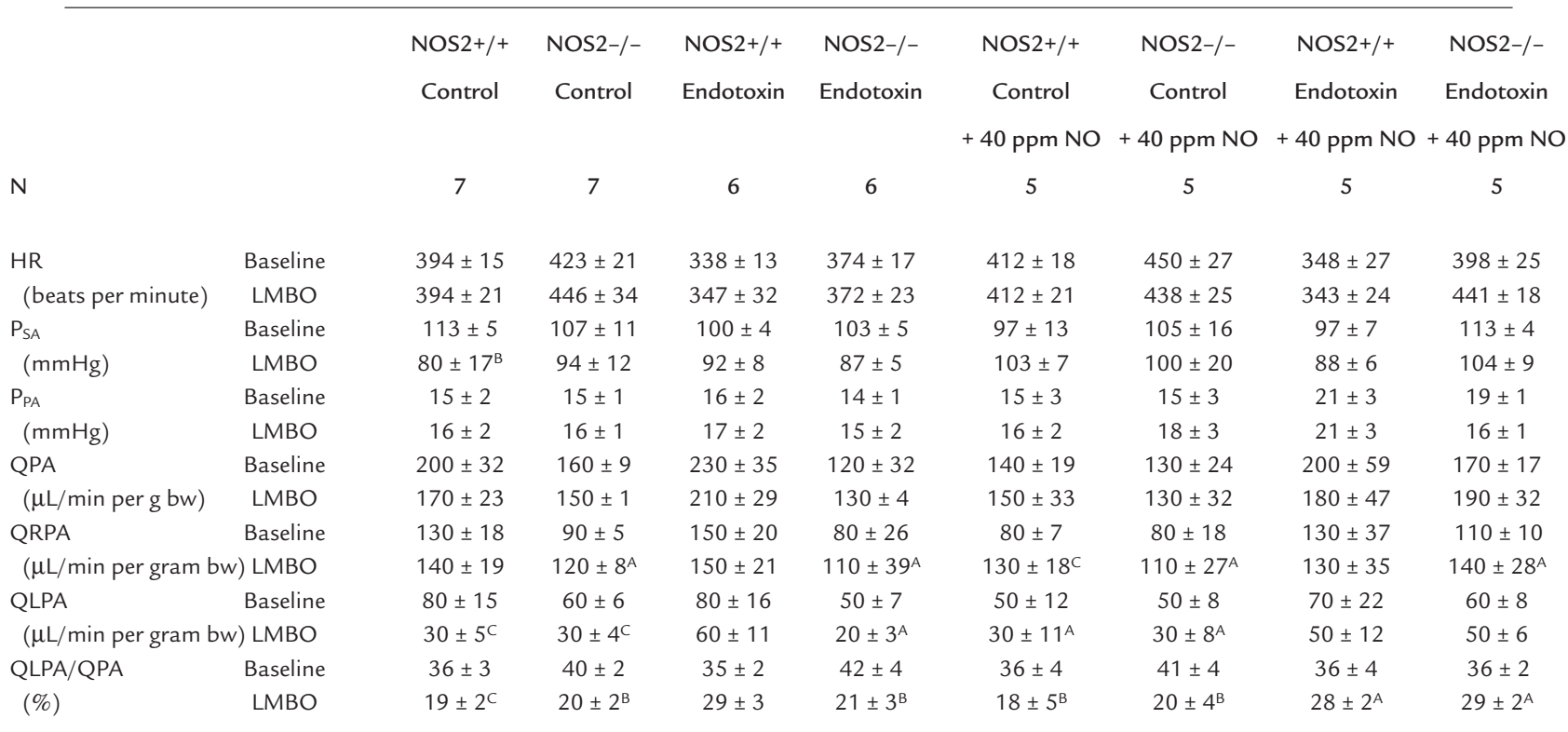

Hemodynamic measurements before LMBO (baseline) and 5 minutes after left lung hypoxia (LMBO) in wild-type mice (NOS2+/+) and NOS2-deficient mice (NOS2-/-) treated with saline (control) or endotoxin (endotoxin) 22 hours before hemodynamic experiments, and with and without inhalation of 40 ppm NO in air for 22 hours (as measured 1 hour after discontinuation of $\mathrm{NO}$ inhalation). $\mathrm{HR}=$ heart rate $\left(\mathrm{min}^{-1}\right), \mathrm{P}_{\mathrm{SA}}=$ mean systemic arterial pressure $(\mathrm{mmHg}), \mathrm{P}_{\mathrm{PA}}=\mathrm{mean}$ pulmonary artery pressure $(\mathrm{mmHg})$, $\mathrm{QPA}=$ flow through right pulmonary artery during left pulmonary artery occlusion $\left(\mu \mathrm{L} \bullet \mathrm{min}^{-1} \bullet \mathrm{g}^{-1} \mathrm{bw}\right), \mathrm{QRPA}=$ flow through right pulmonary artery $\left(\mu \mathrm{L} \bullet \mathrm{min}^{-1} \bullet \mathrm{g}^{-1} \mathrm{bw}\right), \mathrm{QLPA}$ $=$ flow through left pulmonary artery $\left(\mu \mathrm{L}^{\circ} \mathrm{min}^{-1} \bullet \mathrm{g}^{-1} \mathrm{bw}\right), \mathrm{QLPA} / \mathrm{QPA}=$ ratio of flow through left pulmonary artery to flow through right pulmonary artery during transient left pulmonary artery occlusion. All values at baseline before LMBO were compared between groups by ANOVA. The effect of LMBO on each parameter was analyzed in each group by ANOVA with a post hoc comparison. ( ${ }^{A} P<0.05,{ }^{B} P<0.01,{ }^{C} P<0.001$ versus baseline). 
in saline-treated wild-type mice and $50 \pm 11 \%$ in salinetreated NOS2-deficient mice after breathing 40 ppm NO for 22 hours (Figure 3). Except for a modest difference in heart rate, no other differences in pre-LMBO hemodynamics were found between endotoxin-treated and saline-treated mice exposed to prolonged inhalation of 40 ppm NO for 22 hours (Table 1). After prolonged inhalation of $40 \mathrm{ppm} \mathrm{NO}$, endotoxin-treated NOS2-deficient mice demonstrated a marked attenuation of HPV compared with endotoxin-treated NOS2-deficient mice that did not breathe supplemental NO (reduction of QLPA/QPA: $20 \pm 7 \%$ vs. $50 \pm 11 \%$, respectively; $P<0.05$; Figure 3$)$. In contrast, prolonged NO inhalation did not affect the endotoxin-induced impairment of HPV in wildtype mice (reduction of QLPA/QPA: $19 \pm 10 \%$ in endotoxin-treated wild-type mice breathing $40 \mathrm{ppm}$ NO for 22 hours versus $18 \pm 5 \%$ in endotoxin-treated wild-type mice not exposed to NO; Figure 3). In contrast, breathing 4 ppm NO for 22 hours did not impair HPV in endotoxintreated NOS2-deficient mice (reduction of QLPA/QPA: $62 \pm 2 \% ; n=4)$.

Pulmonary vasoreactivity to angiotensin II. To determine whether the impact of endotoxin on HPV was attributable to a nonspecific effect of endotoxin on pulmonary vascular contractile function, we measured the pulmonary vasoconstrictor response to increasing intravenous doses of angiotensin II in saline-treated wild-type mice and wildtype mice 22 hours after endotoxin challenge. PVR increased from $74 \pm 24$ at baseline to $184 \pm 25$ $\mathrm{mmHg} \bullet \mathrm{min} \bullet \mathrm{g} \bullet \mathrm{mL}^{-1}$ at $5.0 \mu \mathrm{g} / \mathrm{kg}$ per minute angiotensin II in saline-treated wild-type mice without endotoxin $(P<$ $0.01)$ and from $55 \pm 11$ to $174 \pm 40 \mathrm{mmHg} \bullet \mathrm{min} \bullet \mathrm{g} \bullet \mathrm{mL}^{-1}$ in endotoxin-challenged wild-type mice $(P<0.001)$. At any angiotensin II infusion dose level, there was no difference in the PVR of endotoxin-treated and saline-treated mice. $\mathrm{P}_{\mathrm{LA}}$ at baseline did not differ between saline-treated wildtype mice $(6 \pm 1 \mathrm{mmHg})$ and endotoxin-treated wild-type mice $(5 \pm 1 \mathrm{mmHg})$, and $\mathrm{P}_{\mathrm{LA}}$ did not change in response to angiotensin II infusion in either group.

Lung wet/dry weight ratios. Wet/dry lung weight ratios did not differ between endotoxin-challenged wild-type (wet weight/dry weight: $5.0 \pm 0.5$ ) and NOS2-deficient mice $(4.6 \pm 0.2)$, or saline-treated wild-type $(4.6 \pm 0.1)$ and saline-treated NOS2-deficient mice $(4.5 \pm 0.1)$. Breathing 4 or 40 ppm NO for 22 hours did not alter the wet/dry lung weight ratios.

\section{Discussion}

To investigate the role of NO and NOS2 in the impairment of HPV in sepsis, we developed an in vivo mouse model to assess the redistribution of pulmonary blood flow in response to unilateral alveolar hypoxia produced by LMBO. In mice not exposed to endotoxin, LMBO doubled left lung PVR, thereby diverting 50\% of left pulmonary blood flow to the right lung and causing a modest decrease in $\mathrm{PaO}_{2}$. Changes in murine pulmonary blood flow distribution measured using ultrasonic flow probes at thoracotomy were closely correlated with measurements obtained using intravenous injection of fluorescent microspheres (see Figure 2a) and were similar to those reported by investigators studying large animal models $(24,25)$. Pulmonary blood flow redistribu- tion induced by bronchial occlusion has been attributed to mechanical factors associated with pulmonary collapse (21), as well as to HPV. In contrast, several in vivo animal studies have demonstrated that the pulmonary blood flow redistribution in response to bronchial occlusion was primarily dependent on changes in $\mathrm{PvO}_{2}$, but not on changes in intrabronchial pressure $(22,26)$. We observed that slow re-expansion of the atelectatic left mouse lung with nitrogen did not reduce the left lung's PVR (Figure 2c), suggesting that in our murine model, the pulmonary vasoconstrictor response to LMBO is also attributable to HPV rather than mechanical factors.

In wild-type mice 22 hours after an endotoxin challenge, we observed that the ability to redistribute pulmonary blood flow in response to regional lung hypoxia was severely impaired, leading to a marked deterioration in systemic arterial oxygenation. This endotoxin-induced impairment of pulmonary blood flow redistribution in the mouse is similar to that observed in awake sheep after intravenous challenge with live bacteria (11) or endotoxin (10). We do not believe that the endotoxin-induced impairment of HPV was attributable to nonspecific dysfunction of the vasomotor contractile apparatus because we found that the ability of angiotensin II to vasoconstrict the pulmonary vasculature did not differ in endotoxin-challenged and saline-treated mice. Moreover, the deleterious effect of endotoxin on the murine pulmonary vasculature was reversible with restoration of HPV at 14 days after endotoxin administration (data not shown).

In NOS2-deficient mice challenged with endotoxin 22 hours earlier, HPV was not impaired and there was preservation of systemic arterial oxygenation during LMBO. Similarly, HPV was preserved in wild-type mice

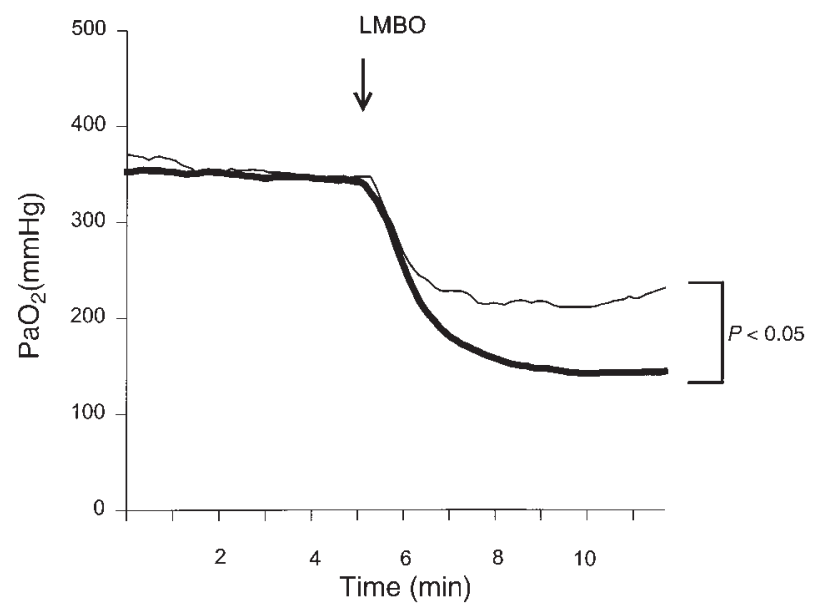

\section{Figure 4}

Effects of regional hypoxia induced by LMBO on the systemic arterial partial pressure of oxygen $\left(\mathrm{PaO}_{2}\right)$ in endotoxin-treated wild-type mice (thick line) and endotoxin-treated NOS2-deficient mice (narrow line). Endotoxin was administered 22 hours before study by an intraperitoneal injection of $10 \mathrm{mg} / \mathrm{kg}$ E. coli endotoxin. Continuous recordings of $\mathrm{PaO}_{2}$ were obtained with a Clark-type oxygen electrode located in the aortic arch. Data are the mean of independent experiments with wild-type mice $(n=$ 5 ) and NOS2-deficient mice $(n=3)$. Note that $\mathrm{LMBO}$ decreased the $\mathrm{PaO}_{2}$ in both groups, but the decrease of $\mathrm{PaO}_{2}$ was more marked in wild-type mice than in NOS2-deficient mice ( $P<0.05 ; 5$ minutes after LMBO). 
treated with L-NIL, a specific inhibitor of NOS2 enzyme activity, 3 hours after endotoxin challenge. These results demonstrate that NOS2 enzyme activity is critical to produce the endotoxin-induced impairment of HPV.

It is unlikely that impairment of HPV in wild-type mice 22 hours after endotoxin challenge is attributable to excess pulmonary $\mathrm{NO}$ levels, as acute administration of L-NIL immediately after LMBO did not restore HPV. These results differ from the findings of Griffiths et al. (12), who observed that 4 hours after rats were challenged with endotoxin, NOS2 inhibitors augmented the pulmonary vasoconstrictor response to both hypoxia and angiotensin II. A possible explanation for these differing results is that Griffiths et al. studied animals at an earlier time after endotoxin challenge, when pulmonary NOS2 is abundant, whereas we studied mice 22 hours after endotoxin challenge, when pulmonary NOS2 enzyme levels are no longer abundant (refs. 12 and 27, unpublished observations). For example, we found that pulmonary cGMP levels were markedly increased 7 hours after endotoxin challenge but had returned to baseline after 22 hours. These results demonstrate that endotoxin-induced pulmonary NOS2 expression is necessary to impair HPV but that continued NOS2 activity is not required for the impairment of HPV measured 22 hours after the endotoxin challenge.

Under certain conditions, NOS2 can produce superoxide, as well as NO (28). We examined whether NO produced by NOS 2 contributed to the endotoxin-induced impairment of HPV by replenishing pulmonary NO levels via inhalation in endotoxin-challenged NOS2-deficient mice. NOS2-deficient mice were challenged with endotoxin and placed in an exposure chamber containing varying concentrations of NO for 22 hours. Pulmonary blood flow redistribution in response to $\mathrm{LMBO}$ was measured 1 hour after removal from the chamber, by which time pulmonary NO levels would not be expected to be elevated. HPV was impaired in endotoxinchallenged NOS2-deficient mice that breathed $40 \mathrm{ppm}$ NO (see Figure 3). In contrast, breathing 4 ppm NO for 22 hours did not impair HPV in endotoxin-treated NOS2-deficient mice. These data suggest that markedly elevated pulmonary NO levels (either produced endogenously by NOS 2 or inhaled) are required to impair HPV. If our observations in mice are extrapolated to human beings, an important clinical implication of our studies is that the administration of high concentrations of inhaled NO to patients with pulmonary inflammation may attenuate HPV, leading to a paradoxical decrease in arterial oxygenation. Moreover, these findings support the current clinical practice of using the lowest effective concentration of inhaled NO when treating patients with acute respiratory failure (29).

In saline-treated wild-type and NOS2-deficient mice, inhalation of 40 ppm NO for 22 hours did not impair HPV when the animals were studied 1 hour after removal from the exposure chamber (see Figure 3). These results suggest that sustained increases in pulmonary NO levels alone are insufficient to cause lasting impairment of HPV. In addition, breathing 40 ppm NO for 22 hours did not further impair HPV in endotoxin-challenged wild-type mice. Thus, it appears that inhaled NO and endotoxin-induced pulmonary NO production are not additive with respect to impairing HPV.

Our studies suggest that the lasting impairment of HPV after endotoxin challenge requires both increased pulmonary $\mathrm{NO}$ levels and additional endotoxin-induced inflammatory products. For example, stimulation of cells by endotoxin or cytokines results in the generation of large amounts of superoxide $\left(\mathrm{O}_{2}^{-}\right)$, which can react with $\mathrm{NO}$ to form peroxynitrite $\left(\mathrm{ONOO}^{-}\right)$. Peroxynitrite is a potent oxidant that can nitrate tyrosine residues in numerous proteins $(30,31)$. High levels of nitrotyrosine have been found in pulmonary cells of endotoxin-challenged animals and human beings with sepsis $(27,31)$. Kristof et al. recently reported that NOS2-deficient mice were less susceptible to endotoxin-induced acute lung injury, associated with a marked decrease in endotoxininduced pulmonary nitrotyrosine immunoreactivity (27). Although the mechanisms responsible for hypoxiainduced contraction of pulmonary vascular smooth muscle cells are incompletely characterized, it is possible that formation of peroxynitrite from $\mathrm{NO}$ and superoxide interferes with the HPV sensor or effector mechanisms by inducing lipid peroxidation, inhibiting mitochondrial electron transport, stimulating tyrosine phosphorylation, or interfering with hypoxia-responsive potassium channels (31).

Sepsis, a major cause of mortality in intensive care units, is the most common cause of acute respiratory distress syndrome (ARDS). Sepsis-induced impairment of HPV leads to increased V/Q mismatching and right-toleft shunting of venous blood, producing arterial hypoxemia. In this study, we observed that NO synthesis by NOS2, as well as additional endotoxin-induced products, is required to impair HPV in endotoxin-treated mice. These findings suggest at least 2 strategies for the prevention of the sepsis-induced impairment of HPV. One method would be to prevent the loss of HPV by inhibiting pulmonary NO production by NOS2. The discovery of new, highly selective inhibitors of NOS2 would offer the advantage of blocking excess NO production by NOS2 with concomitant preservation of regional blood flow regulation by NOS3. A second therapeutic method would be to reduce the levels of the yet unknown septic factors that combine with NO to impair HPV.

\section{Acknowledgments}

The authors thank J. Hromi for technical assistance, Y. Chiao Chang for statistical advice, and M. Takata for helpful comments. This study was supported by United States Public Health Service (grants HL-42397 and HL 55377 to W.M. Zapol and K.D. Bloch). R. Ullrich is supported by a grant from the Max Kade Foundation. K.D. Bloch is an Established Investigator of the American Heart Association. The Massachusetts General Hospital has licensed patents on the use of inhaled NO in respiratory failure, and the authors have a right to receive royalties.

\footnotetext{
1. Rodman, D.M., Yamaguchi, T., Hasunuma, K., O'Brien, R.F., and McMurtry, I.F. 1990. Effects of hypoxia on endothelium-dependent relaxation of rat pulmonary artery. Am. J. Physiol. 258:L207-L214.

2. Voelkel, N.F. 1986. Mechanisms of hypoxic pulmonary vasoconstriction. Am. Rev. Respir. Dis. 133:1186-1195.

3. Ignarro, L.J., Buga, G.M., Wood, K.S., Byrns, R.E., and Chaudhuri, G.
} 
1987. Endothelium-derived relaxing factor produced and released from artery and vein is nitric oxide. Proc. Natl. Acad. Sci. USA. 84:9265-9269.

4. Cremona, G., Wood, A.M., Hall, L.W., Bower, E.A., and Higenbottam, T. 1994. Effect of inhibitors of nitric oxide release and action on vascular tone in isolated lungs of pig, sheep, dog and man. J. Physiol. (Lond.) 481:185-195.

5. Stamler, J.S., Loh, E., Roddy, M.A., Currie, K.E., and Creager, M.A. 1994. Nitric oxide regulates basal systemic and pulmonary vascular resistance in healthy humans. Circulation. 89:2035-2040.

6. Archer, S.L., Tolins, J.P., Raij, L., and Weir, E.K. 1989. Hypoxic pulmonary vasoconstriction is enhanced by inhibition of the synthesis of an endothelium derived relaxing factor. Biochem. Biophys. Res. Commun. 164:1198-1205.

7. Frostell, C.G., Blomqvist, H., Hedenstierna, G., Lundberg, J., and Zapol, W.M. 1993. Inhaled nitric oxide selectively reverses human hypoxic pulmonary vasoconstriction without causing systemic vasodilation. Anesthesiology. 78:427-435.

8. Nathan, C., and Xie, Q.W. 1994. Nitric oxide synthases: roles, tolls, and controls. Cell. 78:915-918.

9. Nussler, A.K., et al. 1992. Stimulation of the nitric oxide synthase pathway in human hepatocytes by cytokines and endotoxin. J. Exp. Med. 176:261-264.

10. Hutchison, A.A., Ogletree, M.L., Snapper, J.R., and Brigham, K.L. 1985 Effect of endotoxemia on hypoxic pulmonary vasoconstriction in unanesthetized sheep. J. Appl. Physiol. 58:1463-1468.

11. Fischer, S.R., et al. 1997. Nitric oxide synthase inhibition restores hypoxic pulmonary vasoconstriction in sepsis. Am. J. Respir. Crit. Care Med. 156:833-839.

12. Griffiths, M.J., Curzen, N.P., Mitchell, J.A., and Evans, T.W. 1997. In vivo treatment with endotoxin increases rat pulmonary vascular contractility despite NOS induction. Am. J. Respir. Crit. Care Med. 156:1-8.

13. Stevens, T., Morris, K., McMurtry, I.F., Zamora, M., and Tucker, A. 1993. Pulmonary and systemic vascular responsiveness to TNF-alpha in conscious rats. J. Appl. Physiol. 74:1905-1910.

14. Fox, G.A., Paterson, N.A., and McCormack, D.G. 1994. Effect of inhibition of NO synthase on vascular reactivity in a rat model of hyperdynamic sepsis. Am. J. Physiol. 267:H1377-H1382.

15. Wu, C.C., Chen, S.J., and Yen, M.H. 1998. Nitric oxide-independent activation of soluble guanylyl cyclase contributes to endotoxin shock in rats. Am. J. Physiol. 275:H1148-H1157.

16. Villamor, E., et al. 1995. Group B streptococcus and E. coli LPS-induced $\mathrm{NO}$-dependent hyporesponsiveness to noradrenaline in isolated intrapulmonary arteries of neonatal piglets. Br. J. Pharmacol. 115:261-266.

17. MacMicking, J.D., et al. 1995. Altered responses to bacterial infection and endotoxic shock in mice lacking inducible nitric oxide synthase. Cell. 81:641-650

18. Laubach, V.E., Shesley, E.G., Smithies, O., and Sherman, P.A. 1995. Mice lacking inducible nitric oxide synthase are not resistant to lipopolysaccharide-induced death. Proc. Natl. Acad. Sci. USA. 92:10688-10692.

19. Schwartz, D., et al. 1997. Inhibition of constitutive nitric oxide synthase (NOS) by nitric oxide generated by inducible NOS after lipopolysaccharide administration provokes renal dysfunction in rats. J. Clin. Invest. 100:439-448.

20. Steudel, W., et al. 1997. Pulmonary vasoconstriction and hypertension in mice with targeted disruption of the endothelial nitric oxide synthase (NOS 3) gene. Circ. Res. 81:34-41.

21. Burton, A.C., and Patel, D.J. 1958. Effect on pulmonary vascular resistance of inflation of the rabbit lungs. J. Appl. Physiol. 12:239-244.

22. Barer, G.R., Howard, P., McCurrie, J.R., and Shaw, J.W. 1969. Changes in the pulmonary circulation after bronchial occlusion in anesthetized dogs and cats. Circ. Res. 25:747-764

23. Glenny, R.W., Bernard, S., and Brinkley, M. 1993. Validation of fluorescent-labeled microspheres for measurement of regional organ perfusion. J. Appl. Physiol. 74:2585-2597.

24. Domino, K.B., et al. 1984. Time course and responses of sustained hypoxic pulmonary vasoconstriction in the dog. Anesthesiology. 60:562-566.

25. Sprague, R.S., Thiemermann, C., and Vane, J.R. 1992. Endogenous endothelium-derived relaxing factor opposes hypoxic pulmonary vasoconstriction and supports blood flow to hypoxic alveoli in anesthetized rabbits. Proc. Natl. Acad. Sci. USA. 89:8711-8715.

26. Pirlo, A.F., Benumof, J.L., and Trousdale, F.R. 1981. Atelectatic lobe blood flow: open vs. closed chest, positive pressure vs. spontaneous ventilation. J. Appl. Physiol. 50:1022-1026.

27. Kristof, A.S., Goldberg, P., Laubach, V., and Hussain, S.N. 1998. Role of inducible nitric oxide synthase in endotoxin-induced acute lung injury. Am. J. Respir. Crit. Care Med. 158:1883-1889.

28. Xia, Y., and Zweier, J.L. 1997. Superoxide and peroxynitrite generation from inducible nitric oxide synthase in macrophages. Proc. Natl. Acad. Sci. USA. 94:6954-6958

29. Zapol, W.M. 1993. Minidose inhaled nitric oxide: less is better. Intensive Care Med. 19:433-434.

30. Haddad, I.Y., et al. 1994. Quantitation of nitrotyrosine levels in lung sections of patients and animals with acute lung injury. J. Clin. Invest. 94:2407-2413.

31. Beckman, J.S., and Koppenol, W.H. 1996. Nitric oxide, superoxide, and peroxynitrite: the good, the bad, and ugly. Am. J. Physiol. 271:C1424-C1437. 